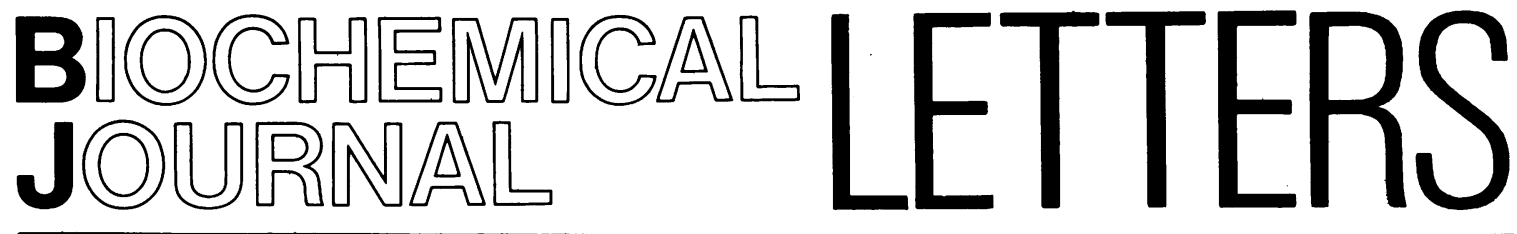

\section{A note on the organization of the} core lipids in porcine low density lipoproteins

Porcine lipoproteins have often been used as a model for study of the molecular composition and molecular organization of serum lipoproteins (Janado et al., 1966; Janado \& Martin, 1968; Calvert \& Scott, 1975; Knipping et al., 1975; Jackson et al., 1976; Jürgens et al., 1981). From the two distinct porcine low density subfractions, $\mathrm{LDL}_{1}$ is found to be similar in size and molecular composition to human LDL. LDL $_{2}$ is smaller and has higher protein and lower cholesteryl ester content. In a small-angle X-ray scattering study it was found that both subfractions exhibit a thermotropic transition (Jürgens et al., 1981), and in the same study it was proposed that below the transition temperature in both LDL subfractions the core lipids are organized in a double-layered arrangement similar to that found in human LDL (Deckelbaum et al., 1975; Laggner et al., 1977; Atkinson et al., 1977; Laggner \& Müller, 1978). As judged from the radial electron density function derived from the original scattering data (best illustrated in Fig. 3 of Jürgens et al., 1981), the arrangement of cholesteryl esters in the core and the size of the core are approximately the same in both LDL subfractions. The two electron-density maxima attributed to the steroid moieties of cholesteryl esters are found to be at about $r_{1}=3.0 \mathrm{~nm}$ and $r_{2}=6.3 \mathrm{~nm}$, essentially the same as in human LDL (Laggner et al., 1977; Atkinson et al., 1977; Laggner \& Müller, 1978). The third maximum, attributed to the particle surface layer composed of protein and phospholipid, is found to be at about $9.0 \mathrm{~nm}$. Thus, the smaller size of $\mathrm{LDL}_{2}$ is indirectly interpreted to result in a smaller separation between the outer cholesteryl ester layer and the surface layer $(2.7 \mathrm{~nm})$ than in other LDL samples studied (3.8nm) (Laggner et al., 1977; Atkinson et al., 1977; Laggner \& Müller, 1978; Bailey, 1981) and in HDL from atherosclerotic pigs, $\mathrm{HDL}_{\mathrm{c}}$ (Atkinson et al., 1978). A different separation between the two outer layers means a completely different arrangement of the interface.

Abbreviations used: LDL, low-density lipoprotein; HDL, high-density lipoprotein.
That fact was not appreciated enough when the double-layered model for the $\mathrm{LDL}_{2}$ core was proposed, since the proposed model is not consistent with other physicochemical data.

Since the ratio of the core lipids to the polar lipids and protein is smaller in $\mathrm{LDL}_{2}$ than in larger particles such as porcine $\mathrm{LDL}_{1}$ and human LDL, it is the volume of the core and not the surface layer that must be significantly smaller in $\mathrm{LDL}_{2}$. It is easily seen from the compositional data that the number of cholesteryl ester molecules is too small to fill the two concentric layers at about 3.0 and $6.3 \mathrm{~nm}$. If the $M_{\mathrm{r}}$ of $\mathrm{LDL}_{2}$ is assumed to be $2 \times 10^{6}$ (Janado et al., 1966; Jürgens et al., 1981) and the $M_{\mathrm{r}}$ of a 'representative' cholesteryl ester molecule 650 , then it follows that each $\mathrm{LDL}_{2}$ particle contains about 970 cholesteryl ester molecules. On the other hand, to fill only the outer layer $(r \simeq 6.3 \mathrm{~nm})$ with the electron-rich moieties of the cholesteryl esters, the steroids, about 1360 molecules are needed. The latter number is obtained with the assumption that within the layer the steroids are tightly packed and that each cholesteryl ester molecule has a cross-section of $36.6 \times 10^{-2} \mathrm{~nm}^{2}$, as deduced from the crystal structure of cholesteryl myristate (Craven \& De Titta, 1976).

The failure of the double-layer model to account for the reduced number of cholesteryl esters in the particle suggests a search for a different interpretation of the original X-ray-scattering data. One of the possibilities is to assume a non-spherical organization of the core, in the manner proposed by Luzzati and coworkers (Luzzati et al., 1979). Another possibility, still in the framework of a spherically symmetric particle, is to assume different phases for the amplitudes of the scattered Xrays. If instead of +-+-- , the +-+-+ sequence is used, the deduced radial electron density distribution curve has only two maxima, one at about $r=4.6 \mathrm{~nm}$ and the other at about $r=8.5 \mathrm{~nm}$ (Jürgens et al., 1981). The inner maximum should indicate the position of the steroid moieties of cholesteryl esters. The layer at $4.6 \mathrm{~nm}$ can accommodate about 730 cholesteryl ester molecules. The remaining cholesteryl esters and triacylglycerols might form a liquid droplet in the centre of the particle. They cannot form another ordered layer, because the volume encompassed by 
the layer at about $r=2.0 \mathrm{~nm}$ would be too small to accommodate the acyl or iso-octyl chains of the ordered cholesteryl ester molecules. The arguments for a single-layered organization are essentially the same as those discussed for a slightly smaller cholesterol-rich particle, $\mathrm{HDL}_{\mathrm{c}}$ (Atkinson et al., 1978).

For the proposed single-layered spherically symmetric organization of the ordered core in $\mathrm{LDL}_{2}$, the separation of the two maxima of the radial electron density function is about $3.9 \mathrm{~nm}$. This value is essentially the same as that found for other cholesterol-rich lipoproteins below the transition temperature. The constant separation of about $3.8 \mathrm{~nm}$ between the surface layer and the adjacent cholesteryl ester layer, independent of size and perhaps even of class of lipoproteins, may mean that the surface layer serves as a boundary or a template at which an ordered layer of cholesteryl esters is formed. Whether or not the ordering of lipids will take place depends on the conditions in the core (concentration of triacylglycerols, temperature, volume, etc.).

A part of this work was done in the stimulating atmosphere of the I. Physikalisches Institut der Universität zu Köln (Germany). The work was supported by the Self-Managing Scientific Community of Croatia (Yugoslavia).

\section{J. N. HERAK}

Faculty of Pharmacy and Biochemistry, University of Zagreb, A. Kovačića 1, 41000 Zagreb, Yugoslavia

(Received 20 January 1984)

Atkinson, D., Deckelbaum, R. J, Small, D. M. \& Shipley, G. G. (1977) Proc. Natl. Acad. Sci. U.S.A. 74, 1042-1046

Atkinson, D., Tall, A. R., Small, D. M. \& Mahley, R. W. (1978) Biochemistry 17, 3930-3933

Bailey, C. J. (1981) Int. J. Biol. Macromol. 3, 140-143

Calvert, G. D. \& Scott, P. J. (1975) Atherosclerosis 22, 583-599

Craven, B. M. \& De Titta, T. (1976) J. Chem. Soc. Perkin II, 814-822

Deckelbaum, R. J., Shipley, G. G., Small, D. M., Lees, R. S. \& George, P. K. (1975) Science 190, 392-394

Jackson, R. L., Taunton, O. D., Segura, R., Gallagher, J. G., Hoff, H. F. \& Gotto, A. M., Jr. (1976) Comp. Biochem. Physiol. 53B, 245-253

Janado, M. \& Martin, W. G. (1968) Can. J. Biochem. 46, 875-878

Janado, M., Martin, W. B. \& Cook, W. H. (1966) Can. J. Biochem. 44, 1201-1209

Jürgens, G., Knipping, G. M. J., Zipper, P., Kayushina, R., Degovics, G. \& Laggner, P. (1981) Biochemistry 20, 3231-3237

Knipping, G. M. J., Kostner, G. M. \& Holasek, A. (1975) Biochim. Biophys. Acta 393, 88-99
Laggner, P. \& Müller, K. (1978) Q. Rev. Biophys. 11, 371425

Laggner, P., Degovics, G., Müller, K. W., Glatter, O., Kratky, O., Kostner, G. \& Holasek, A. (1977) HoppeSeyler's Z. Physiol. Chem. 358, 771-778

Luzzati, V., Tardieu, A. \& Aggerbeck, L. P. (1979) J. Mol. Biol. 131, 435-473

\section{The cholesteryl-ester core of porcine low-density lipoproteins}

In the evaluation of X-ray data, model-dependent assumptions are normally avoided as far as possible until the state is reached where a given shape, size and electron-density distribution has to be filled with chemical constituents. Therefore, apart from the justifiable assumption of quasispherical symmetry (see discussion on pp. 3235 and 3236 of Jürgens et al., 1981) our results on the structure of porcine $\mathrm{LDL}_{2}$ are independent of $a$ priori hypotheses. The electron-density profiles showing two maxima around 3.0 and $6.3 \mathrm{~nm}$ (Fig. 4 of Jürgens et al., 1981), both for $\mathrm{LDL}_{1}$ and $\mathrm{LDL}_{2}$, have been obtained from direct deconvolution of the distance distribution function $p(r)$ (Glatter, 1981 ) involving no phase ambiguity and providing the optimal weighted-least-squares approximation to the experimental data. Thus, despite the intrinsic low-resolution nature of X-ray smallangle-scattering results, they are, at present, the most reliable data on porcine LDL structure and hence the yardstick against which any model of molecular architecture has to be put.

The primary criterion in the search for a suitable molecular model is the agreement between the volumes required for any chemical constituent and the volume available within the structure. In $\mathrm{LDL}_{2}$, with $31.6 \%$ (by weight) cholesteryl esters and $3.6 \%$ triacylglycerols, and a molecular mass of $(2.0 \pm 0.2) \times 10^{6}$, the volume required for those apolar lipids is $(1.23 \pm 0.12) \times 10^{3} \mathrm{~nm}^{3}$, using a value of $1.06 \mathrm{~cm}^{3} / \mathrm{g}$ for their specific volume. Packed into a sphere, this would correspond to a radius of $6.6 \mathrm{~nm}$. Note that this estimation involves no assumption on the molecular conformation. Errors in the specific volume are negligible as they are strongly diminished by the third-root correlation to the radius. The agreement of this radius with the dimensions of the temperature-sensitive domain in the radial electron density distributions is very good (see Fig. 3 in Jürgens et al., 1981). Accepting that mainly the cholesteryl esters are responsible for the thermotropic behaviour of LDL, it must be concluded, as in all other cases of LDL subfractions, that the apolar constituents fill

Abbreviation used: LDL, low-density lipoprotein. 